\title{
La mayor concentración de hemoglobina materna durante el embarazo se asoció a un riesgo aumentado de muerte fetal
}

\author{
Stephansson O, Dickman P, Johansson A, Cnattingiu S. JAMA. 2000;284:2611-2617
}

\section{Objetivo}

Estudiar las asociaciones entre la concentración de hemoglobina en el primer control prenatal, la modificación de dicha concentración en el transcurso del embarazo y el riesgo de muerte fetal.

\section{Diseño}

Estudio caso-control poblacional.*

Lugar
Suecia

\section{Pacientes}

De los partos realizados entre 1987 y 1996 se incluyeron las 702 mujeres primíparas con feto muerto ocurridos a las 28 semanas de gestación o a posteriori y se eligieron aleatoriamente 702 controles de embarazadas primíparas con hijos vivos que hubieran dado a luz en el mismo hospital y en el mismo año que los casos.

\section{Medición del resultado principal}

Riesgo de muerte fetal, clasificado como malformado o no malformado, anteparto o intraparto, término o pretérmino, y de peso adecuado o pequeño para la edad gestacional, comparado con la concentración de hemoglobina en el primer control prenatal, las modificaciones semanales en la concentración de hemoglobina en el transcurso del embarazo. En el análisis multivariado*, se controló por edad materna, índice de masa corporal, tabaquismo, estado socioeconómico, y semana en la que se realizó la primera medición de hemoglobina.

\section{Resultados}

El análisis multivariado* mostró que las mujeres con concentraciones de hemoglobina de $14,6 \mathrm{~g} / \mathrm{dl}$ o superiores en el primer control prenatal con respecto a las mujeres que tenían concentraciones de 12.6 a $13.5 \mathrm{~g} / \mathrm{dl}$ tuvieron un mayor riesgo de muerte fetal (OR 1.8; IC 95\% 1.0 a 3.3). Este riesgo se incrementó ligeramente cuando el análisis se restringió a los fetos muertos anteparto sin malformaciones (OR 2.0; IC 95\% 1.1 a 3.8). Cuando en el análisis se tomaron los fetos muertos de pretérmino, y pequeños para la edad gestacional no malformados, los OR fueron de 2.7 (IC 95\% 1.1 a $6-4$ ) y 4.2 (IC $95 \% 1.3$ a 13.9) respectivamente. En este ultimo subgrupo (fetos muertos pequeños para la edad gestacional) cuando se excluyeron las mujeres con pre-eclampsia y eclampsia el OR aumento aún mas (15.1 IC 95\% 3.0 a 75.5).

Las modificaciones semanales en la concentración de hemoglobina no se asociaron con el riesgo de muerte fetal, si bien la disminución en la concentración muestra ser un factor protector. La anemia, considerada como una concentración de hemoglobina $<11.0 \mathrm{~g} / \mathrm{dl}$ no se asoció significativamente al riesgo de muerte fetal en el análisis multivariado (OR 1.2; IC 95\% 0.5 a 2.7).

\section{Conclusiones}

La alta concentración de hemoglobina en el primer control prenatal parecería estar asociado con un riesgo aumentado de muerte fetal, especialmente en los fetos muertos de pretérmino y en los fetos muertos pequeños para la edad gestacional.

\section{Comentario}

Las características de este estudio deben ser resaltadas en cuanto a que se realizó en una población homogénea como la sueca, con un cuidado prenatal estandarizado y que incluyó mas de 700 fetos muertos y 700 controles con fetos vivos que expresan el $96 \%$ y el $97 \%$ de las historias clínicas revisadas. Asimismo los dosajes de hemoglobina fueron registrados prospectivamente durante el control gestacional, por lo que el sesgo de recuerdo (recall bias en inglés) * es muy poco probable. Numerosos factores confundidores tales como la edad materna o el tabaquismo fueron controlados, sin embargo otros potenciales confundidores conocidos como estado nutricional y nivel de actividad física de la madre no pudieron ser recolectados, por no hallarse presentes en las historias clínicas.

Los resultados del presente estudio muestran que el riesgo de muerte fetal se duplica en las mujeres con altas concentraciones de hemoglobina, y este riesgo es aún mayor si se analiza en los subgrupos de fetos muertos de pretérmino y pequeños para la edad gestacional.

Curiosamente la mayoría de las guías de control prenatal tanto en los países centrales como en los en vías en desarrollo sugieren la administración de suplementos de hierro aún en los casos en que la concentración de hemoglobina es alta. Sin embargo una reciente revisión de la Cochrane Library1 expresa como conclusión que la suplementación rutinaria de hierro no produce efecto de- tectable alguno en los resultados maternos o fetales.

Aparentemente este estudio refuerza el concepto hasta ahora malinterpretado que la expansión del volumen plasmático y la disminución de lacconcentración de hemoglobina son respuestas fisiológicas durante el embarazo. La expansión del volumen plasmático es un factor importante en el crecimiento fetal y ya son varios los estudios que han informado un aumento en la incidencia de bajo peso asociada a una concentración de hemoglobina aumentada. El mecanismo por el cual la expansión plasmática estimularía el crecimiento fetal se desconoce pero la reducción de la viscosidad sanguínea podría favorecer el flujo sanguíneo en el espacio intervelloso. En efecto los valores altos de hemoglobina se asocian a infartos placentarios, mientras que la hemodilución al prevenir la trombosis en la circulación uteroplacentaria estimularía el crecimiento y la nutrición fetal.

Por lo tanto a partir de este y otros trabajos sería recomendable por un lado evaluar con prudencia la administración rutinaria de hierro sobre todo en los embarazos que no muestran anemia, y por otro lado debería de considerarse un embarazo de alto riesgo a todo aquel que muestre altas concentraciones de hemoglobina. No obstante y dado el diseño del presente estudio (caso-control), la asociación entre concentración de hemoglobina y muerte feta requeriría de nuevos trabajos prospectivos que confirmen dicha hipótesis.

\section{Dr. Mario Sebastiani [ Servicio de Obstetricia Hospital Italiano de Buenos Aires ]}

